ZOOLOGIA 30 (2): 151-156, April, 2013

http://dx.doi.org/10.1590/S1984-46702013000200005

\title{
Threats to and viability of the giant anteater, Myrmecophaga tridactyla (Pilosa: Myrmecophagidae), in a protected Cerrado remnant encroached by urban expansion in central Brazil
}

\author{
Milena F. Diniz ${ }^{1,2} \&$ Daniel Brito \\ ${ }^{1}$ Laboratório de Ecologia Aplicada e Conservação, Departamento de Ecologia, Instituto de Ciências Biológicas, Universidade \\ Federal de Goiás, Campus Samambaia, Caixa Postal 131, 74001-970, Goiânia, GO, Brazil. \\ ${ }^{2}$ Corresponding author. E-mail: midiniz3@hotmail.com
}

\begin{abstract}
Urbanization poses a serious threat to wildlife populations inhabiting native vegetation remnants surrounded by the expanding urban and suburban sprawl. The close contact with human activities causes not only direct impacts, such as habitat loss, but also indirect negative effects, such as population isolation, roadkills and anthropogenic fires. The Parque Nacional de Brasília is a large Cerrado remnant almost completely surrounded by the city of Brasília, in central Brazil. Here, we use population viability analysis to model the impacts of urbanization on a population of Myrmecophaga tridactyla (Linnaeus, 1758) inhabiting that park. Our results show that roadkill mortality is by far the most serious threat to the long-term persistence of the giant anteater in the study site. The implementation of measures to better control vehicle speed in the vicinity of the park is urgently needed if we expect the giant anteater population to be effectively protected in the Parque Nacional de Brasília.
\end{abstract}

KEY WORDS. Extinction; inbreeding; PVA; roadkill; wildfire.

The Cerrado is one of the richest savannas of the world (Myers et al. 2000, Mittermeier et al. 2005). It is also one of the world's most threatened ecosystems due to human activities (Myers et al. 2000, Mittermeier et al. 2005). Therefore, it is no surprise that it is considered as a priority region for global conservation actions (Olson \& Dinerstein 2002, SANDERson et al. 2002, Hoekstra et al. 2005, Mittermeier et al. 2005, Brooks et al. 2006). The history of large-scale human impacts in the Cerrado, where cattle ranching and crop production (mainly soy) have dramatically increased in the last decades, is relatively recent (KLINK \& Moreira 2002).

The beginning of a serious human occupation of the cerrado by humans dates back to the 1950's, when the country's new capital (Brasília) was built. Human population growth and urbanization quickly followed (IBGE 2011). Up to the present day, the Cerrado has lost almost $80 \%$ of its original vegetation (Mittermeier et al. 2005), and only 5.5\% of the ecoregion is legally protected (a meager $1.4 \%$ as strict protected areas) (Mittermeier et al. 2005).

The Federal District region (Brasília and its surrounding municipalities) was listed as an area of extreme high importance for the conservation of the biodiversity of the Cerrado (MMA 2007). It is the major urban center in central Brazil. Brasília was planned to house 500,000 inhabitants, but its current population is estimated at 2.6 million inhabitants (IBGE 2011). Human population growth and urban sprawl are the main threats to the biodiversity in the Federal District region.
The Parque Nacional de Brasília $\left(42,389\right.$ ha) $\left(15^{\circ} 35^{\prime}-15^{\circ} 45^{\prime} \mathrm{S}\right.$, $48^{\circ} 05^{\prime}-48^{\circ} 53^{\prime} \mathrm{W}$ ) was created in 1961 , and at present it is completely surrounded by urban and suburban sprawl, and its perimeter is almost completely encircled by high-traffic roads (DF-001, DF-095, BR-020 and BR-251).

The giant anteater, Myrmecophaga tridactyla (Linnaeus, 1758), occurs in open grasslands and savanna habitats in the Neotropics (GARDNER 2007). It is listed as threatened both in the IUCN Red List of Threatened Species (IUCN 2011) and in Brazil's national red list (MACHADO et al. 2008). The major threats to the giant anteater are habitat loss (urbanization), roadkills, hunting, fires and feral dogs (IUCN 2011). There is a native giant anteater population in the Parque Nacional de Brasília (Nascimento \& Campos 2011). Our objectives in this contribution are: (1) to estimate the viability of the giant anteater population in the Parque Nacional de Brasília; (2) to estimate the relative impacts of isolation due to urbanization, roadkills and anthropogenic fires on the viability of this population; and (3) to propose management procedures that might improve the survival of that population.

\section{MATERIAL AND METHODS}

To model the viability and the effects of roadkills and fire on the giant anteater population, we used the PVA software VORTEX (LACY et al. 2005). We used VORTEX to simulate population dynamics and extinction risk for a series of 
scenarios: 1) baseline scenario, where we assumed no inbreeding, no roadkills and no anthropogenic fires to occur; 2 ) inbreeding scenario, where we included the inbreeding depression tool in VORTEX (3.14 lethal equivalents, see RALLS et al. 1998), assuming that the urban expansion of Brasília caused the giant anteater population to become isolated; 3 ) wildfire scenario, where we included a 5\% chance for the population being hit by a wildfire (Silveira et al. 1999); and 4) roadkill scenarios, where we included mortality due to the high traffic on the roads that surround the Cerrado remnant; we modeled three roadkill mortality intensities $(8,17$ or 25 individuals killed per year). Roadkills are a serious threat to the giant anteater's populations in the Cerrado (CÁCEREs 2011). Even though the Parque Nacional de Brasília is almost completely surrounded by high-traffic roads, there is no monitoring program of roadkills set in place for this protected area. Therefore, we decided to incorporate this threat in our model using three roadkill impact scenarios: 0.05 of the population affected (or eight individuals killed per year); 0.10 (or 17 individuals killed per year); and 0.15 (or 25 individuals killed per year). For each scenario, the duration of each simulation was set at 100 years, and the model was run 1,000 times. The carrying capacity for the study site was calculated based on an estimated density of 0.4 giant anteaters $/ \mathrm{km}^{2}$ (Miranda 2004). We assumed that the remnant was fully occupied at the beginning of a simulation, and set the initial population size of each scenario as equal to its carrying capacity. We considered as viable those scenarios that showed a $>95 \%$ probability of persistence during the 100 year period modeled in the study (SHAFFer 1981, SOulé 1987).

Giant anteaters are solitary and may be active during the day or night, depending on the temperature (CAmilo-Alves \& Mourão 2006, MourÃo \& MEdRI 2007). It is more active in open habitats and rests in woodlands (MOURão \& MEDRI 2007). Their diet consists of ants and termites (GARDNER 2007). A single young is born per reproductive event (GARDNER 2007). Life history data used as input in VORTEX was obtained from previous PVA studies on the giant anteater published in the scientific literature (MirAnda 2004). A scheme of giant anteater biological data and parameter changes in scenarios modeled is given in Table I.

Table I. Life history parameters (based on MiRANDA 2004) and threat scenarios used to model the viability of Myrmecophaga tridactyla population in Parque Nacional de Brasília. For a detailed description of input parameters, see LACY et al. (2005).

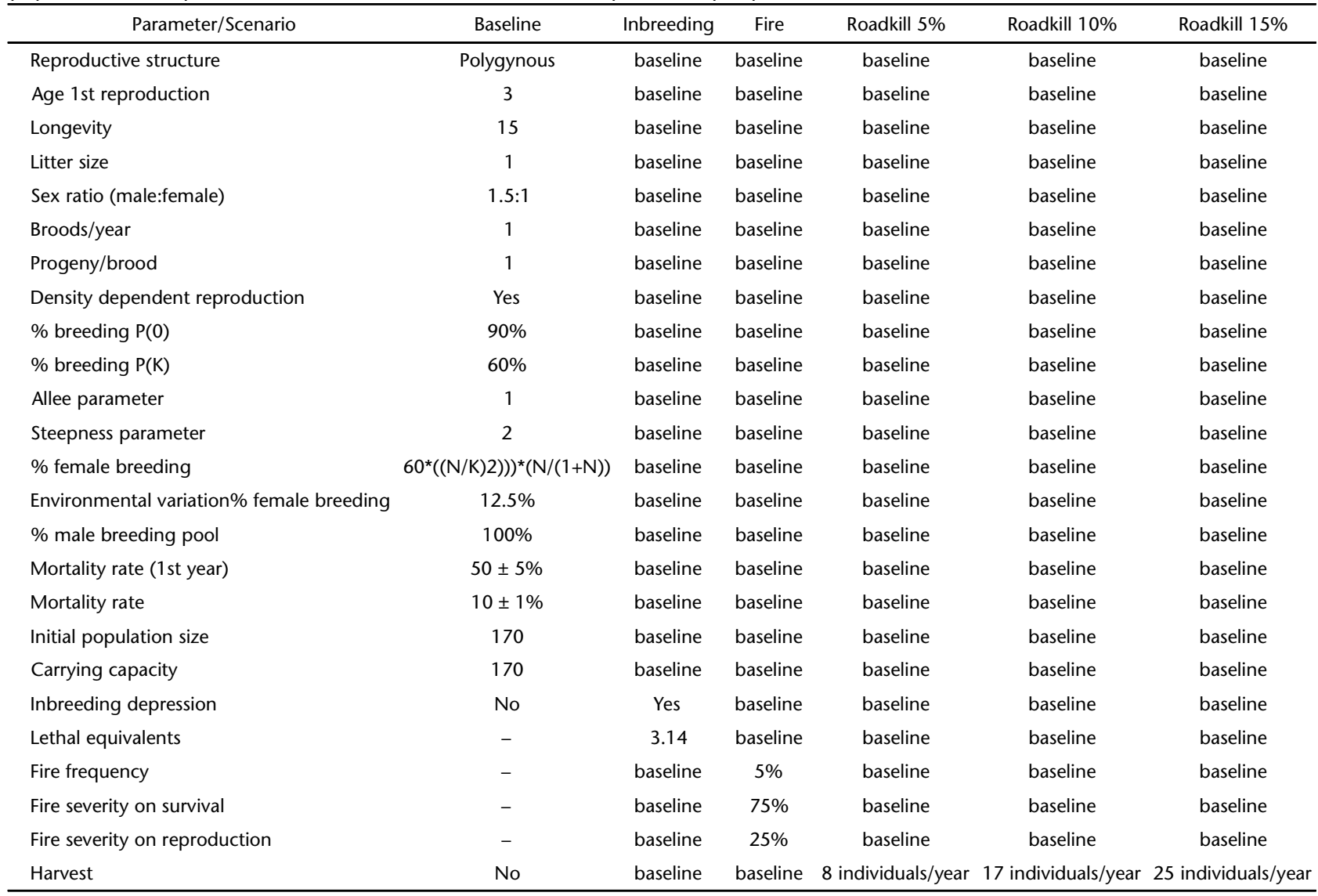




\section{RESULTS}

The results of the VORTEX modeling show that, in the baseline scenario (no inbreeding and roadkills), the giant anteater population in the Parque Nacional de Brasília is viable within the 100 years of the simulation (Fig. 1). Fires, which are a natural phenomenon in the Cerrado, do not affect population viability (Fig. 1). Under this scenario, the population retains most of its original genetic diversity (Fig. 2) after the simulations, but there is a decline in the mean population size (Fig. 3).

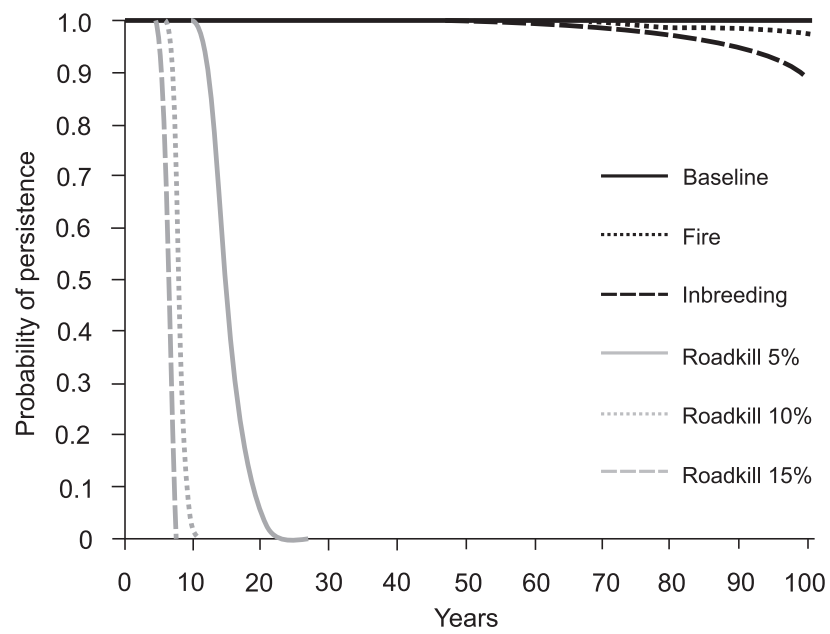

Figure 1. Persistence probability estimated under the baseline and threat scenarios (see text) used to model the population of Myrmecophaga tridactyla at Parque Nacional de Brasília.

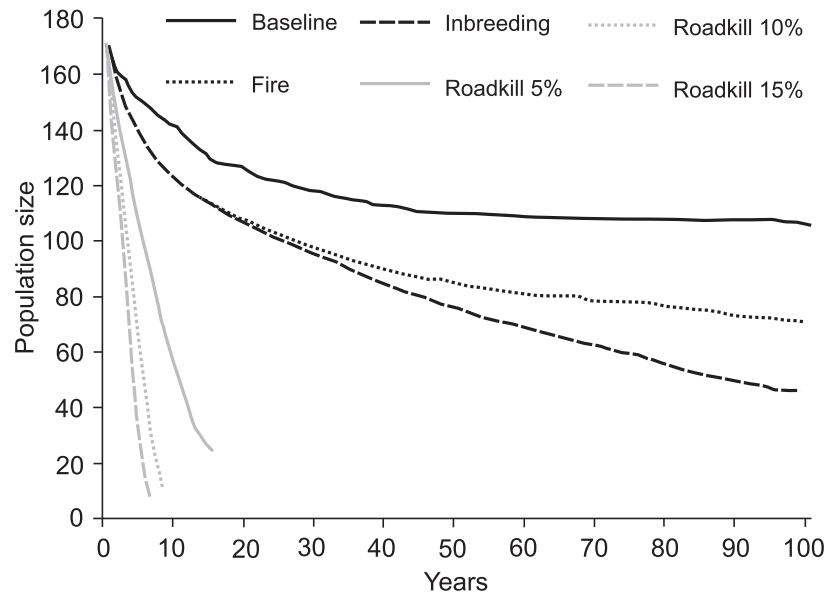

Figure 2. Estimated population size under the baseline and threat scenarios (see text) used to model the population of Myrmecophaga tridactyla at Parque Nacional de Brasília. Population size estimates for all scenarios were conducted only up to the point where population persistence was $>50 \%$.
The results of our models suggest that roadkills are the most serious threat to the persistence of the giant anteater population in the Parque Nacional de Brasília (Fig. 1). The giant anteater population is very sensible to roadkills, and even the removal of just a few individuals increases the probability of extinction of the population (Fig. 1). The removal of eight or more individuals due to roadkills, in our simulations, resulted in a rapid extirpation of the population from the study area (Fig. 1). Even though the impact of inbreeding is not as drastic as that of roadkills, inbreeding also has the potential to threaten the persistence of the population (Fig. 1). Inbreeding and fires caused declines in population size in scenarios where the population did not go extinct (Fig. 2). Inbreeding and fires also resulted in greater loss of genetic diversity than that predicted by the baseline scenario (Fig. 3).

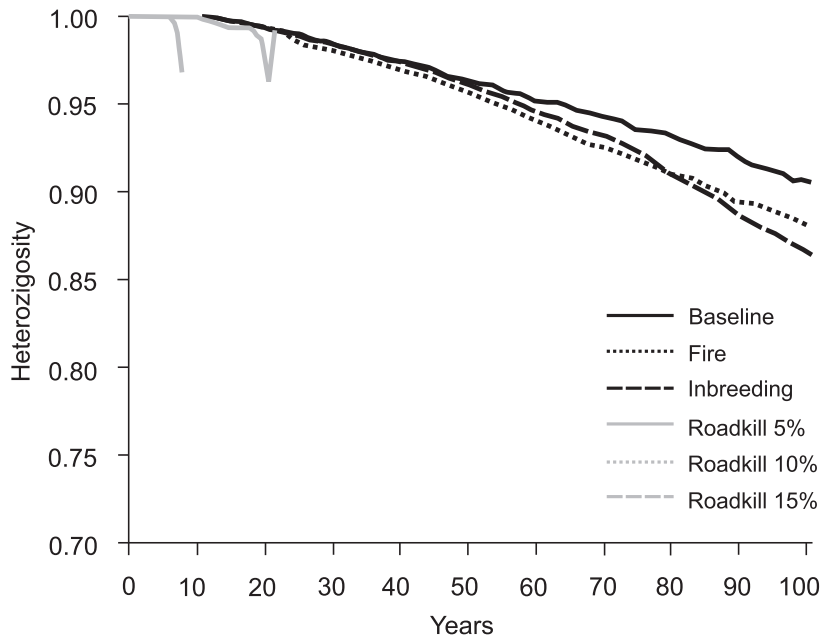

Figure 3. Estimated heterozigosity under the baseline and threat scenarios (see text) used to model the population of Myrmecophaga tridactyla at Parque Nacional de Brasília. Heterozigosity estimates for all scenarios were conducted only up to the point where population persistence was $>50 \%$.

\section{DISCUSSION}

The intense process of urbanization that has taken place in the last few decades poses a serious hazard for the giant anteater population of the Parque Nacional de Brasília. Roadkills are the leading human impact on terrestrial vertebrate mortality (FormAn \& AlEXANDER 1998). Roadkill mortality may result in population declines, population bottlenecks, and increased extinction risks (Forman et al. 2003). Road width, vehicle traffic levels, paving, and speed limits affect roadkill rates (Forman \& Alexander 1998, Orlowsky \& NowaK 2006). Medium-sized and large mammals are highly mobile, which increases their chances to encounter roads, to try to cross them, and to be killed by 
vehicles. Medium-sized and large mammals are especially susceptible on two-lane high-speed roads (Forman \& Alexander 1998). Giant anteaters have already been documented to suffer from roadkill mortality in the Cerrado (e.g., CÁCERES et al. 2010), and in the study area. The giant anteater population of the Parque Nacional de Brasília is completely surrounded by two-lane high-traffic roads (Fig. 1), and as a consequence, individuals dispersing or trying to forage in adjoining areas must cross these roads, becoming vulnerable to passing vehicles. MiRANDA (2004) observed a mortality rate of one individual per year in the Parque Nacional das Emas, a site with much lower human density, vehicular traffic and far from major urban centers. The human population in Brasília has increased from 1.2 million in 1980 to 2.6 million in 2010 (IBGE 2011), and the number of vehicles in the capital of Brazil has increased dramatically in the last few years.

Wildfires are a natural phenomenon in the Cerrado. However, the large human population living close to the Parque Nacional de Brasília causes a disruption in the natural fire regime of the Cerrado, and anthropogenic fires occur more frequently. Our simulations show that genetic diversity is lost and the population declines in the presence of fires. Wildfires have already been reported to kill giant anteaters in the Cerrado, culling a significant portion of the population (SILVEIRA et al. 1999). Individuals suffer from the direct mortality due to the impacts of fires, but those who survive are capable of using burnt areas to forage (Prada \& Marinho-Filho 2004). Giant anteaters can escape from fires by taking refuge in gallery forests along river banks or fleeing to areas adjacent to the Parque Nacional de Brasília (Silveira et al. 1999). Unfortunately, due to the isolation of the national park, when a fire occurs, individuals fleeing the affected area will have to cross the roads surrounding the park, increasing the chances of roadkills.

The predictions derived from our simulations might be viewed as optimistic because we did not model scenarios evaluating other known threats to the giant anteater population in the study area, such as feral dogs (LACERDA et al. 2009). It has been demonstrated that feral dogs cause an edge effect in the Brasília Parque Nacional de Brasília, and giant anteaters avoid the outer skirts of the park (Lacerda et al. 2009). Dogs come from urban and suburban areas close to the park: stray dogs enter the park through a garbage dump located in the vicinity of the protected area (LACERDA et al. 2009). Even though giant anteaters are hunted in certain areas (e.g., KOSTER 2008) there is no evidence of that they are hunted [by wild dogs] in the Parque Nacional de Brasília. However, even though humans are not hunting giant anteaters in the study site, there is the possibility that feral dog packs may hunt down giant anteaters, as they come into the national park. Feral dog attacks have been listed as a possible cause for the decline of the giant anteater population in the Parque Nacional de Brasília (Horowitz 1992). Another reason why our results may be perceived as optimistic is that we have considered the giant anteater population at its carrying capacity in the beginning of all scenarios modeled. One possible limitation of our approach is that some of the values of the parameters used were estimated from another population (Parque Nacional das Emas, see Miranda 2004). Some population parameters are determined by the evolution of the lineage that originated the species, and show little or no variation across different populations of the same species. However, other parameters are more affected by the local environmental conditions (e.g., mortality rates). The stochastic nature of the viability model already incorporates some of this local variation. The parameters that could have significant variation across populations were exactly those we chose to model different scenarios in order to evaluate local threats that reflect better local reality.

A genetic study conducted at the Parque Nacional das Emas found that the giant anteater population of that area has low levels of genetic diversity and high levels of inbreeding (Collevatti et al. 2007). The population estimated for the Parque Nacional de Brasília is much smaller than that inhabiting the Parque Nacional das Emas. Our results show that if urbanization results in isolation of the giant anteater population and inbreeding, this might increase the risk of extinction and cause population declines, but inbreeding is not expected to cause loss of genetic diversity (see results above). However, we did not model a scenario with the possible synergistic effects of fire and inbreeding. Fires may depress population size and cause a genetic bottleneck, resulting in loss of genetic diversity (e.g., CollevatTi et al. 2007).

The results of our simulations suggest that the three scenarios we have modeled threat the giant anteater population under scrutiny in the following order of importance: roadkills, fires, inbreeding. In order to improve the chances of survival of the giant anteater population at the Parque Nacional de Brasília, we recommend that some management actions are implemented. Because our analysis shows that roadkills are by far the most serious threat, we suggest that speed bumps and speed traps (pardais in Portuguese) are installed in the roads close to the park. Speed limits in the vicinity to the park should also be re-evaluated, and maximum speeds decreased. These measures should be complemented by a more strict enforcement of traffic laws and more rigorous punishment for infractions. The construction of wildlife overpasses could also mitigate roadkills. Decreasing roadkill mortality is likely to bring great benefits not only for the giant anteater population, but also for other wide-ranging wildlife species found at the site (e.g., the manned wolf). We also recommend that a fire management action plan, specifically for the study area, should be developed. Even though wildfires are a natural process in the Cerradoand should not be controlled/suppressed, anthropogenic fires should be extinguished as fast as possible.

Management actions to counteract the negative effects of inbreeding in the short term could include the construction of wildlife passes (e.g., Clevenger \& Waltho 2000, van Wieren \& 
Worm 2001), to facilitate connectivity between the giant anteater population in the Parque Nacional de Brasília and other populations nearby. Besides improving connectivity, such passages could help decrease roadkill mortality, and provide an escape route for individuals when fires hit the park. Because there is yet too much to be investigated about the population parameters of the giant anteater at the Parque Nacional de Brasília, we also suggest the implementation of a population monitoring program for the giant anteater. Such program could generate site-specific population parameters to refine the viability models in the future.

The creation, implementation and enforcement of a management plan for the giant anteater population in the Parque Nacional de Brasília are of utmost importance. It may give one of the first inhabitants of Brasília (its native giant anteater population), a chance to coexist with the new neighbors in town.

\section{ACKNOWLEDGEMENTS}

Milena F. Diniz thanks CAPES for the PIBIC scholarship. Daniel Brito's work is funded by CNPq (Project \# 305631/2009-8).

\section{LITERATURE CITED}

Brooks, T.M.; R.A. Mittermeier; G.A.B. da Fonseca; J. Gerlach; M. Hoffmann; J.F. Lamoreux; C.G. Mittermeier; J.D. Pilgrim \& A.S.L. RoDRIGUES. 2006. Global biodiversity conservation priorities. Science 313: 58-61.

CÁCERES, N.C. 2011. Biological characeristics influence mammal road kill in an Atlantic Forest - Cerrado interface in southwestern Brazil. Italian Journal of Zoology 78 (3): 379-389.

Cáceres, N.C.; W. Hannibal; D.R. Freitas; E.L. Silva; C. Roman \& J. Casella. 2010. Mammal occurrence and roadkill in two adjacent ecoregions (Atlantic Forest and Cerrado) in southwestern Brazil. Zoologia 27 (5): 709-717.

Camilo-Alves, C.S.P. \& G. Mourão. 2006. Responses of a specialized insectivorous mammal (Myrmecophaga tridactyla) to variation in ambient temperature. Biotropica 38 (1): 52-56.

Clevenger, A.P. \& N. Waltho. N. 2000. Factors influencing the effectiveness of wildlife underpasses in Banff National Park, Alberta, Canada. Conservation Biology 14 (1): 47-56.

Collevatti, R.G.; K.C.E. Leite; G.H.B. Miranda \& F.H.G. Rodrigues. 2007. Evidence of high inbreeding in a population of the endangered giant anteater, Myrmecophaga tridactyla (Myrmecophagidae), from Emas National Park, Brazil. Genetics and Molecular Biology 30 (1): 112-120.

Forman, R.T.T. \& L.E. AleXander. 1998. Roads and their major ecological effects. Annual Review of Ecology and Systematics 29 (1): 207-231.

Forman, R.T.T.; D. Sperling; J.E. Bissonette; A.P. Clevenger; C.D. Cutshall; V.H. Dale; L. Fahrig; R. France; C.R. Goldman; K. Heanue; J.A. Jones; F.J. Swanson; T. Turrentine \& T.C. Winter.
2003. Road ecology: science and solutions. Washington, Island Press.

Gardner, A.L. 2007. Mammals of South America volume 1: marsupials, xenarthrans, shrews and bats. Chicago, The University of Chicago Press.

Hoekstra, J.M.; T.M. Boucher; T.H. Ricketts \& C. Roberts. 2005. Confronting a biome crisis: global disparities of habitat loss and protection. Ecology Letters 8 (1): 23-29.

Horowitz, C. 1992. Plano de manejo do Parque Nacional de Brasília: avaliação da metodologia de planejamento adotada, execução e resultados alcançados no decênio 79/ 89. Brasília, Universidade de Brasília.

IBGE. 2011. Estimativas populacionais para os municípios brasileiros. Brasília, IBGE.

IUCN. 2011. IUCN Red List of threatened species. Gland, IUCN/SSC.

Klink, C.A. \& A.G. Moreira. 2002. Past and current human occupation and land use, p. 69-90. In: P.S. OliveIRA \& R.J. MARQUis (Eds). The Cerrados of Brazil: ecology and natural history of a Neotropical savanna. New York, Columbia University Press.

Koster, J.M. 2008. Giant anteaters (Myrmecophaga tridactyla) killed by hunters with dogs in the Bosawas Biosphere Reserve, Nicaragua. The Southwestern Naturalist 53 (3): 414416.

Lacerda, A.C.R.; W.M. Tomas \& J. Marinho-Filho. 2009. Domestic dogs as an edge effect in the Brasília National Park, Brazil: interactions with native mammals. Animal Conservation 12 (5): 477-487.

LACY, R.C.; M. Borbat \& J.P. POLLAK. 2005. VORTEX: A Stochastic simulation of the extinction process. Version 9.99. Illinois, Chicago Zoological Society.

Machado, A.B.M.; G.M. Drummond \& A.P. Paglia. 2008. Livro vermelho da fauna brasileira ameaçada de extinção. Brasília, Ministério do Meio Ambiente.

Miranda, G.H.B. 2004. Ecologia e conservação do tamanduábandeira (Myrmecophaga tridactyla, Linnaeus, 1758) no Parque Nacional das Emas. Brasília, Universidade de Brasília.

Mittermeier, R.A.; P.R. Gil; M. Hoffman; J. Pilgrim; T. Brooks; C.G. Mittermeier; J. Lamoreux \& G.A.B. Da Fonseca. 2005. Hotspots revisited: Earth's biologically richest and most endangered terrestrial ecoregions. Mexico City, CEMEX.

MMA. 2007. Áreas prioritárias para a conservação, uso sustentável e repartição dos benefícios da biodiversidade brasileira. Brasília, Ministério do Meio Ambiente, Série Biodiversidade 31 .

Mourão, G. \& I.G. Medri. 2007. Activity of a specialized insectivorous mammal (Myrmecophaga tridactyla) in the Pantanal of Brazil. Journal of Zoology 271 (2): 187-192.

Myers, N.; R.A. Mittermeier; C.G. Mittermeier; G.A.B. da Fonseca \& J. Kent. 2000. Biodiversity hotspots for conservation priorities. Nature 403: 853-858. 
Nascimento, J.L. \& I.B. CAmpos. 2011. Atlas da fauna brasileira ameaçada de extinção em unidades de conservação federais. Brasília, ICMBio.

Olson, D.M. \& E. Dinerstein. 2002. The global 200: priority ecoregions for global conservation. Annals of the Missouri Botanical Garden 89 (2): 199-224.

OrLowsKi, G. \& L. NowAK. 2006. Factors influencing mammal roadkills in the agricultural landscape of south-western Poland. Polish Journal of Ecology 54 (2): 283-294.

Prada, M. \& J. Marinho-Filho. 2004. Effects of fire on the abundance of Xenarthrans in Mato Grosso, Brazil. Austral Ecology 29 (5): 568-573.

Ralls, K.; J.D. Ballou \& A.R. Templeton. 1988. Estimates of lethal equivalents and the cost of inbreeding in mammals.
Conservation Biology 2: 185-93.

Sanderson, E.W.; M. Jaiteh; M.A. Levy; K.H. Redford; A.V. Wannebo \& G. Woolmer. 2002. The human footprint and the last of the wild. BioScience 52 (10): 891-904.

Shaffer, M.L. 1981. Minimum population sizes for species conservation. BioScience 31: 131-134.

Silveira, L.; F.H.G. Rodrigues; A.T.A. Jácomo \& J.A.F. Diniz-Filho. 1999. Impact of wildfires on the megafauna of Emas National Park, central Brazil. Oryx 33 (2): 108-114.

Soulé, M.E. 1987. Viable populations for conservation. Cambridge, Cambridge University Press.

van Wieren, S.E. \& P.B. Worm. 2001. The use of a motorway wildlife overpass by large mammals. Netherlands Journal of Zoology 51 (1): 97-105.

Submitted: 27.IV.2012; Accepted: 21.XII.2012.

Editorial responsibility: Heraldo L. de Vasconcelos 